\title{
Electrospray Ionization Multiple-Stage Linear Ion-trap Mass Spectrometry for Structural Elucidation of Triacylglycerols: Assignment of Fatty Acyl Groups on the Glycerol Backbone and Location of Double Bonds
}

\author{
Fong-Fu Hsu and John Turk \\ Mass Spectrometry Resource, Division of Endocrinology, Diabetes, Metabolism, and Lipid research, \\ Department of Internal Medicine, Washington University School of Medicine, St. Louis, Missouri, USA
}

\begin{abstract}
Linear ion-trap multiple-stage mass spectrometric approach $\left(\mathrm{MS}^{n}\right)$ towards nearly complete structural elucidation of triacylglycerol (TAG) including (1) assignment the fatty acid substituents on the glycerol backbone and (2) location of the double bond(s) on the unsaturated fatty acyl groups is reported. The characterization is established by the findings that $\mathrm{MS}^{2}$ on the $[\mathrm{M}+\mathrm{Li}]^{+}$ions of TAG yields more abundant ions reflecting losses of the outer fatty acid substituents either as free acids (i.e., $\left[\mathrm{M}+\mathrm{Li}-\mathrm{R}_{1} \mathrm{CO}_{2} \mathrm{H}\right]^{+}$and $\left[\mathrm{M}+\mathrm{Li}-\mathrm{R}_{3} \mathrm{CO}_{2} \mathrm{H}\right]^{+}$ions) or as lithium salts (i.e., $\left[\mathrm{M}+\mathrm{Li}-\mathrm{R}_{1} \mathrm{CO}_{2} \mathrm{Li}\right]^{+}$and $\left[\mathrm{M}+\mathrm{Li}-\mathrm{R}_{3} \mathrm{CO}_{2} \mathrm{Li}\right]^{+}$ions) than the ions reflecting the similar losses of the inner fatty acid substituent (i.e., $\left[\mathrm{M}+\mathrm{Li}-\mathrm{R}_{2} \mathrm{CO}_{2} \mathrm{Li}\right]^{+}$and $\left[\mathrm{M}+\mathrm{Li}-\mathrm{R}_{2} \mathrm{CO}_{2} \mathrm{Li}\right]^{+}$ions). Further dissociation $\left(\mathrm{MS}^{3}\right.$ of $\left[\mathrm{M}+\mathrm{Li}-\mathrm{R}_{n} \mathrm{CO}_{2} \mathrm{H}\right]^{+}(n=1,2$, or 3 ) gives rise to the ion series locating the double bonds along the fatty acid chain. These ions arise from charge-remote fragmentations involving $\beta$-cleavage with $\gamma-\mathrm{H}$ shift, analogous to those seen for the unsaturated long-chain fatty acids characterized as initiated ions. Significant differences in abundances in the ion pairs reflecting the additional losses of the fatty acid moieties, respectively, were also seen in the $\mathrm{MS}^{3}$ spectra of the $\left[\mathrm{M}+\mathrm{Li}-\mathrm{R}_{n} \mathrm{CO}_{2} \mathrm{H}\right]^{+}$and $[\mathrm{M}+$ $\left.\mathrm{Li}-\mathrm{R}_{n} \mathrm{CO}_{2} \mathrm{Li}\right]^{+}$ions, leading to confirmation of the fatty acid substituents on the glycerol backbone. $\mathrm{MS}^{n}$ on the $[\mathrm{M}+\mathrm{Na}]^{+}$and $\left[\mathrm{M}+\mathrm{NH}_{4}\right]^{+}$adduct ions also affords location of fatty acid substituents on the glycerol backbone, but not the position of the double bond(s) along the fatty acid chain. Unique ions from internal losses of the glycerol residues were seen in the $\mathrm{MS}^{3}$ spectra of $\left[\mathrm{M}+\mathrm{Alk}-\mathrm{R}_{n} \mathrm{CO}_{2} \mathrm{H}\right]^{+}(n=1,2,3)$ and of $\left[\mathrm{M}+\mathrm{Alk}^{-} \mathrm{R}_{n} \mathrm{CO}_{2} \mathrm{Alk}\right]^{+}(\mathrm{Alk}=\mathrm{Li}, \mathrm{Na}$, $\mathrm{NH}_{4} ; n=1,3$ ). They are signature ions for glycerides and the pathways leading to their formation may involve rearrangements. (J Am Soc Mass Spectrom 2010, 21, 657-669) () 2010 American Society for Mass Spectrometry
\end{abstract}

$\mathrm{H}$ igh-energy CAD with a tandem sector instrument permits structural characterization of triacylglycerol (or triacylglyceride) (TAG) as sodiated adducts desorbed by FAB, leading to identify each fatty acid substituent and positions of fatty acid substituents on the glycerol backbone. However, the sensitivity is poor and the application in elucidation of the location of double bond(s) for the unsaturated fatty acid substituents has not been demonstrated [1]. Highenergy CAD product-ion spectra of the sodiated adducts of TAG obtained with tandem sector instrument coupled with ESI were unsatisfactory for structural characterization, but those from the $\left[\mathrm{M}+\mathrm{NH}_{4}\right]^{+}$ions identified the fatty acid substituents, nevertheless, are not informative for assignment of the fatty acid sub-

Address reprint requests to Dr. F.-F. Hsu, Department of Internal Medicine, Washington University School of Medicine, 660 S. Euclid, Box 8127, St. Louis, MO 63110, USA. E-mail: fhsu@im.wustl.edu stituents on the glycerol backbone [1]. Similarly, tandem quadrupole mass spectra of the $[\mathrm{M}+\mathrm{Na}]^{+}$ions of TAG did not contain structurally informative fragment ions, but those from $\left[\mathrm{M}+\mathrm{NH}_{4}\right]^{+}$ions contained fragment ions that identify the fatty acid groups [2]. Neither the positions of the fatty acid substituents on the glycerol backbone nor the locations of double bonds in unsaturated fatty acid chains could be determined from these spectra [2]. Recently, Pittenauer and Allmaier demonstrated high-energy CAD using MALDITOF/RTOF-MS for characterization of TAGs as alkali adduct ions. The product ions from $[\mathrm{M}+\mathrm{Na}]^{+}$ions of TAG afford determination of the position of fatty acid substituents on the glycerol backbone and in some favorable cases the location of double bonds or hydroxy groups. However, the method is limited by the insufficient precursor ion gating after $\mathrm{MS}^{1}$ (gating window of $4 \mathrm{Da})$, and ion species differed by $2 \mathrm{Da}$ cannot be separated [3]. 
By contrast, tandem quadrupole [4] and quadrupole ion-trap [5] product-ion spectra from the $[\mathrm{M}+\mathrm{Li}]^{+}$ions of TAG is readily applicable for identification of the fatty acid substituents and location their position on the glycerol backbone. Skimmer CAD on the lithiated adduct ion of TAG, followed by tandem quadrupole mass spectrometry on the dilithiated adduct ions of fatty acid substituents generated by skimmer CAD are applicable for location of double bonds. But the method for reliable location of the unsaturated sites for the fatty acid chain in TAG mixtures remains untested [4]. The employment of ozone electrospray ionization and ozone induced dissociation mass spectrometry to unveil the double bond position of trieicosatetraenoin and trioleoryglycerol standards was recently reported by Thomas et al., but assignment of the fatty acid substituents on the glycerol backbone has not been demonstrated [6-8]. The method also required a special set-up to generate harmful ozone gas to be emitted to an ion-trap instrument. Herein, we report a multiple-stage (MS $\left.{ }^{n}\right)(n=2$, $3,4)$ mass spectrometric approach with an LIT instrument for near-complete characterization of TAG as the $[\mathrm{M}+\mathrm{Li}]^{+}$ions, including identification of fatty acid substituents, the site of double bond of fatty acyl substituents and their positions on the glycerol backbone. The application of this LIT MS ${ }^{n}$ method on the $[\mathrm{M}+$ $\mathrm{Na}]^{+}$and $\left[\mathrm{M}+\mathrm{NH}_{4}\right]^{+}$ions of TAG for structural characterization and the mechanism(s) underlying the fragmentation processes leading to ion formation are also discussed.

\section{Experimental}

\section{Material and Chemicals}

Triacylglycerol standards of rac-glyceryl-1,3-dipalmitate2-oleate [(16:0/ $\left.\left.\Delta^{9} 18: 1 / 16: 0\right)-T A G\right]$, rac-glyceryl-2,3dipalmitate-1-oleate $\left[\left(\Delta^{9} 18: 1 / 16: 0 / 16: 0\right)-T A G\right]$, racglyceryl-1-palmitate-2-oleate-3-stearate $\left[\left(16: 0 / \Delta^{9} 18: 1 /\right.\right.$ 18:0)-TAG], rac-glyceryl-1-palmitate-2-stearate-3-oleate [(16:0/18:0/ $\left.\left.\Delta^{9} 18: 1\right)-T A G\right], \quad$ rac-glyceryl-1,3-distearate2-oleate [(18:0/ $\left.\left.\Delta^{9} 18: 1 / 18: 0\right)-T A G\right]$, rac-glyceryl-2,3distearate-1-oleate $\left[\left(\Delta^{9} 18: 1 / 18: 0 / 18: 0\right)-T A G\right]$, and tripalmitin [(16:0/16:0/16:0)-TAG] were purchased from Matreya (Pleasant Gap, PA). Synthetic triarachidonin $\left[\left(\Delta^{5,8,11,14} 20: 4 / \Delta^{5,8,11,14} 20: 4 / \Delta^{5,8,11,14} 20: 4\right)\right.$-TAG] and trilinolein $\left[\left(\Delta^{9,12} 18: 2 / \Delta^{9,12} 18: 2 / \Delta^{9,12} 18: 2\right)\right.$-TAG] standards were purchased from NuChek Prep (Elysian, MN). 1,3( $\left.\mathrm{d}_{5}\right)$-Diheptadecanoyl-2-(10Z-heptadecenoyl)-glycerol $\left[\mathrm{d}_{5}-\left(17: 0 / \Delta^{10} 17: 1 / 17: 0\right)-T A G\right]$ was purchased from Avanti Polar lipid (Alabaster, AL). All TAG standards are $>98 \%$ purity. Solvents and other chemicals were obtained from Fisher Chemical (Suwanee, GA, USA).

\section{Mass Spectrometry}

Low-energy CAD tandem mass spectrometry experiments were conducted on a Finnigan (San Jose, CA) linear ion-trap (LIT) mass spectrometer (MS) with Xcali- bur operating system. Triacylglycerols were dissolved in chloroform/methanol $(1 / 4)$ at final concentration of $10 \mathrm{pmol} / \mu \mathrm{L}$ and lithium hydroxide was added to achieve a final $\left[\mathrm{Li}^{+}\right]$concentration of $1 \mathrm{mM}$ before infusion $(2 \mu \mathrm{L} / \mathrm{min})$ to the ESI source, where the skimmer was set at ground potential, the electrospray needle was set at $4.5 \mathrm{kV}$, and temperature of the heated capillary was $350{ }^{\circ} \mathrm{C}$. The automatic gain control of the ion trap was set to $5 \times 10^{4}$, with a maximum injection time of $200 \mathrm{~ms}$. Helium was used as the buffer and collision gas at a pressure of $1 \times 10^{-3}$ mbar $(0.75$ mTorr). The $\mathrm{MS}^{n}$ experiments were carried out with an optimized relative collision energy ranging from $16 \%$ to $25 \%$ and with an activation q value at 0.25 , and the activation time at $30-100 \mathrm{~ms}$ to leave a minimal residual abundance of precursor ion (around 20\%). The isolation window for the precursor ions were set at $1 \mathrm{Da}$. Mass spectra were accumulated in the profile mode, typically for 3-10 $\min$ for $\mathrm{MS}^{n}(n=2,3$, and 4) spectra. The mass resolution of the instrument was tuned to $0.6 \mathrm{Da}$ at half peak height.

\section{Results and Discussion}

TAG molecules that differ only with respect to the fatty acyl groups at $s n-1$ and $s n-3$, such as $(\mathrm{A} / \mathrm{B} / \mathrm{C})-\mathrm{TAG}$ versus $(C / B / A)-T A G$ (where $A, B$, and $C$ are distinct fatty acid residues) are enantiomers and cannot be distinguished by the present mass spectrometric approach. In this premise for assignment of the fatty acid substituents on the glycerol backbone as described in the text, only the fatty acid substituent assigned to $s n-2$ is specific, and the fatty acid substituents assigned to $s n-1$ and at $s n-3$ is exchangeable (i.e., $\mathrm{A} / \mathrm{B} / \mathrm{C}$ )-TAG and (C/B/A)-TAG are not distinguishable). No effort was made to determine the chirality of TAGs in this study.

\section{Structural Determination of the TAG Species that Possesses Different Fatty Acid Substituents $(A / B / C-T A G ; A \neq B \neq C)$}

Upon resonance excitation in an ion-trap, the $[\mathrm{M}+\mathrm{Li}]^{+}$ ions of TAG yielded abundant fragment ions corresponding to $\left[\mathrm{M}+\mathrm{Li}-\mathrm{R}_{n} \mathrm{CO}_{2} \mathrm{H}\right]^{+}$and $[\mathrm{M}+\mathrm{Li}-$ $\left.\mathrm{R}_{n} \mathrm{CO}_{2} \mathrm{Li}\right]^{+}$(where $n$ denotes the glycerol carbon to which the fatty acid is esterified), which identify the fatty acid substituents. The differential formation of these ions also leads to the location of the fatty acid substituents on the glycerol backbone, similar to those previously observed with a tandem quadrupole instrument [4]. As shown in Figure 1a, the LIT MS ${ }^{2}$ spectrum of the $[\mathrm{M}+\mathrm{Li}]^{+}$ion of $(16: 0 / 18: 1 / 18: 0)-T A G$ at $m / z 867$ contain ions at $m / z 611,583$, and 585, reflecting neutral losses of palmitic acid (16:0), stearic acid (18:0), and oleic acid (18:1), respectively. Ions at $m / z 605,577$, and 579 reflect neutral losses of these fatty acids as the lithium salts. 

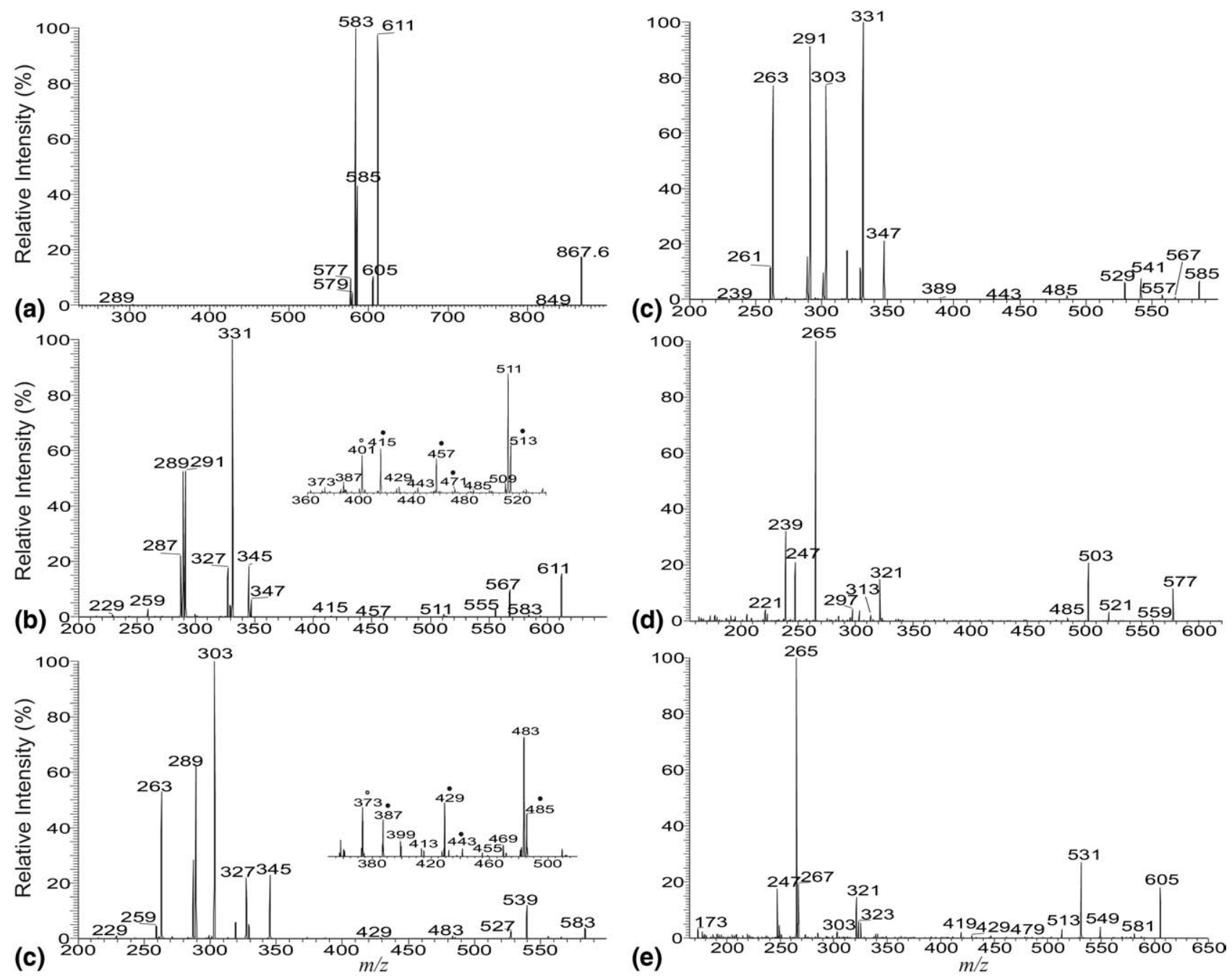

Figure 1. The LIT MS ${ }^{2}$ spectrum of the $[\mathrm{M}+\mathrm{Li}]^{+}$ion of the $16: 0 / 18: 1 / 18: 0-\mathrm{TAG}$ at $\mathrm{m} / \mathrm{z} 867(\mathbf{a})$, its MS $^{3}$ spectra of the ions at $\mathrm{m} / z 611(867 \rightarrow 611)(\mathbf{b})$, at $\mathrm{m} / \mathrm{z} 583(867 \rightarrow 583)(\mathbf{c})$, at $\mathrm{m} / \mathrm{z} 585(867 \rightarrow 585)$ $(\mathbf{d})$, at $m / z 577(867 \rightarrow 577)(\mathbf{e})$, and at $m / z 605(867 \rightarrow 605)(\mathbf{f})$. In the subsets (panel $\mathbf{b}$ and $\mathbf{c})$, the ions labeled with filled circle identified the position of double bond(s).

The ions at $m / z 583$ and 611 are of similar abundance, but are significantly more abundant than the ion at $\mathrm{m} / \mathrm{z}$ 585; the ions at $\mathrm{m} / \mathrm{z} 605$ and 577 are also of similar abundance but are more abundant than the ion at $\mathrm{m} / \mathrm{z}$ 579. The results indicate that neutral loss of the $s n-2$ fatty acid substituent either as a free fatty acid or as a lithium salt was less abundant than the corresponding losses of either the $s n-1$ or the $s n-3$ fatty acid substituent, resulting in assignment of the fatty acid substituents and their position on the glycerol backbone. These results are consistent with the notion that the $\alpha$-hydrogen of the fatty acid substituent at $s n-2$ that participates in the formation of the ions at $m / z 611$ and 583 via elimination of the 16:0-fatty acid at $s n-1$ and of the 18:0-fatty acid at $s n-3$ (Scheme 1a) is more labile than that located at sn-1 or $s n-3$, which involves the loss of the adjacent 18:1-fatty acid at $s n$-2 (i.e., the $m / z 585$ ion), leading to a greater abundance of the ions at $\mathrm{m} / \mathrm{z} 583$ and 611 than the $\mathrm{m} / \mathrm{z}$ 585 ion $[9,10]$.
Further dissociation of the ion at $m / z 611(867 \rightarrow 611$, Figure $1 b$ ) gives rise to $m / z 331$, arising from loss of the 18:1-fatty acid at $s n-2$ as an $\alpha, \beta$-unsaturated fatty acid (Scheme 1a, route $a_{1}{ }^{\prime \prime}$ ). This is in agreement with the presence of the ion at $\mathrm{m} / \mathrm{z} 287$, corresponding to a lithiated 18:2-fatty acid (Scheme $\mathbf{1 a}$, route $a_{2}^{\prime \prime}$ ). The results support the mechanism that the primary loss of the fatty acid substituents involves the participation of the $\alpha$-hydrogen of the neighboring fatty acid substituent and the 5-member intermediate has been formed $[4,11]$. The spectrum also contains the ions at $\mathrm{m} / \mathrm{z} 345$ and 327 arising from losses of the 18:0-fatty acid at $s n-1$ as a ketene and as an acid, respectively, along with the ions at $\mathrm{m} / \mathrm{z} 289$ and 291, corresponding to the lithiated ions of 18:1- and 18:0-fatty acids, respectively. This loss of the fatty acid substituent at $s n-1$ (or $s n-3$ ), followed by further elimination of the $s n-2$ fatty acid as an $\alpha, \beta-$ unsaturated fatty acid is further evidenced by the IT MS ${ }^{3}$ spectrum of the ion at $m / z 583(867 \rightarrow 583$, Figure 1c), in 
(a)

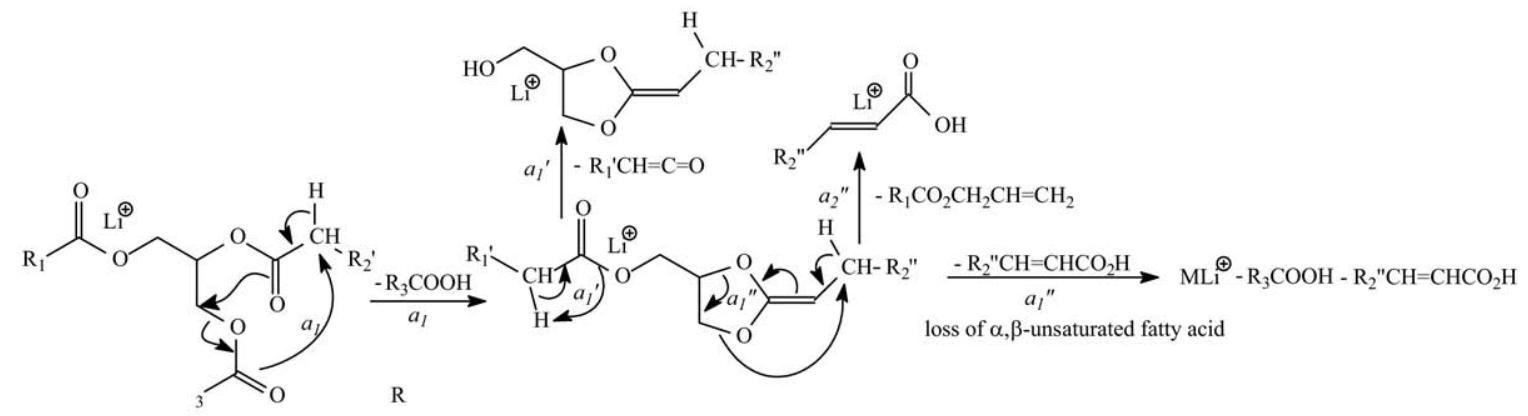

(b)

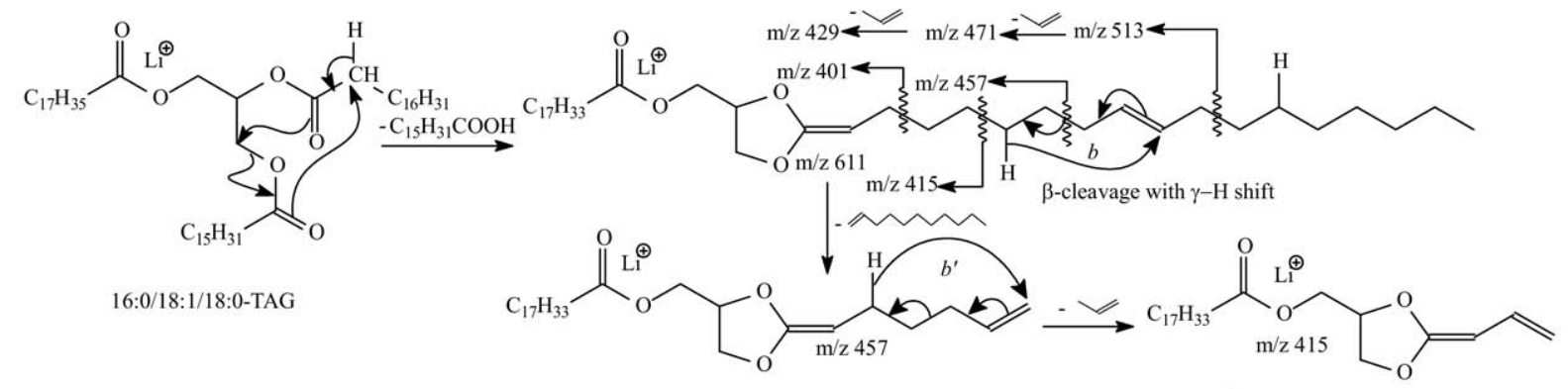

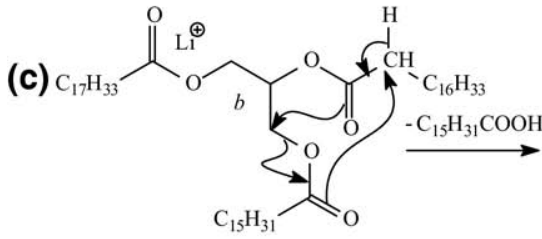

16:0/18:0/18:1-TAG

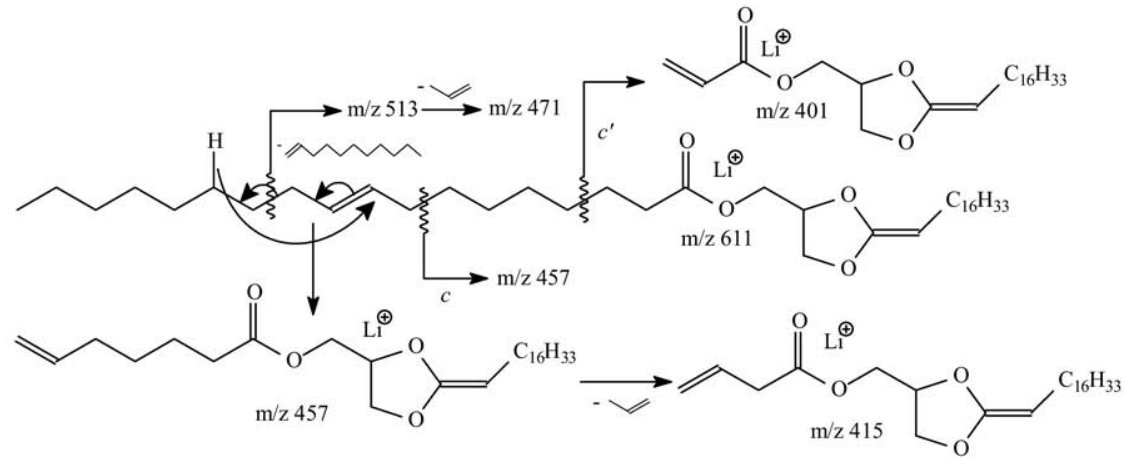

Scheme 1. The mechanisms proposed for fragmentation of TAG (a), the $\beta$ cleavage with $\gamma$-hydrogen shift mechanisms leading to location of double bond(s) for 16:0/18:1/18:0-TAG (b), and for 16:0/18:0/18:1-TAG (c). *All the schemes as shown do not imply that the fragmentation is a one-step process.

which the ion at $m / z 303$, arising from loss of the 18:1-fatty acid at $s n-2$ as an $\alpha, \beta$-unsaturated fatty acid (loss as 18:2) is prominent, while the ions at $m / z 345$ and 327 represent further loss of the 16:0-fatty acid at $s n-1$ as a ketene and as a fatty acid, respectively. The observation of these ions is also consistent with the presence of the ions at $\mathrm{m} / \mathrm{z} 289,287$, and 263 that respectively represent a lithiated 18:1-, 18:2, and a 16:0-fatty acid ions.

The ions at $\mathrm{m} / \mathrm{z} 513$ and 457 (Figure $1 \mathrm{~b}$, inset) may arise from charge-remote fragmentation (CRF) that involves $\beta$-cleavage with rearrangement of $\gamma-\mathrm{H}$ (Scheme $1 \mathbf{b}$, route b); whereas the ions at $\mathrm{m} / \mathrm{z} 415$ (457-propylene), 471 (513-propylene), and 429 (471-propylene) arise from consecutive $\beta$-cleavage with McLafferty rearrangement (Scheme $\mathbf{1 b}$, route $b^{\prime}$ ) [11]. These ions are analogous to the ions at $m / z 197,141,99,155,113$ seen in the MS $^{2}$ spectrum of the dilithiated ion of $\Delta^{9} 18: 1$ [12], suggesting that the double bond of the 18:1-fatty acid substituent at $s n-2$ is located at C(9). Similarly, the $\mathrm{MS}^{3}$ spectrum of $\mathrm{m} / \mathrm{z} 583$ (Figure 1c, inset) also contains the ions at $\mathrm{m} / \mathrm{z}$
$485,429,387,443,401$, which are 28 Da lighter than the analogous ions at $m / z 513,457,415,471$, and 429 seen in Figure $1 \mathrm{~b}$. The results also show that the double bond of the 18:1-fatty acid moiety is located at C(9). The combined results from $\mathrm{LIT} \mathrm{MS}^{n}(n=2,3)$ on the $[\mathrm{M}+\mathrm{Li}]^{+}$ ions of TAG readily afford near-complete structural characterization of the major regioisomer, including assignment of its fatty acid substituents on the glycerol backbone, and location the double bonds along the unsaturated fatty acid chain.

The MS ${ }^{3}$ spectrum of the ion at $\mathrm{m} / z 585(867 \rightarrow 585$, Figure 1d) is dominated by the ion at $m / z 331$ and 303, arising from losses of the 16:0-fatty acid (loss as 16:1FA) at $s n-1$ and 18:0-fatty acid (loss as 18:1-FA) at $s n-3$ as an $\alpha, \beta$-unsaturated fatty acids, respectively. The ions at $m / z 567$ (585-18), 557 (585-28), 541 (585-44) may arise from losses of $\mathrm{H}_{2} \mathrm{O}, \mathrm{CO}, \mathrm{CO}_{2}$, respectively; while the $\mathrm{m} / \mathrm{z} 529$ (585-56) ion may arise from cleavage of glycerol residue (loss of [glycerol $-2 \mathrm{H}_{2} \mathrm{O}$ ]) involving rearrangements (Discussion later). The ion of $\mathrm{m} / \mathrm{z} 529$ gives rise to $m / z 485$ (529-44) by loss of $\mathrm{CO}_{2}$ as previously reported 
[11]. The analogous ions arising from the similar losses were also seen in Figure $1 b$ and $c$.

Further dissociation of the ions at $m / z 577(867 \rightarrow 577$, Figure 1e) gives rise to ions at $\mathrm{m} / \mathrm{z} 265$ and 239, representing the 18:1- and 16:0-acylium ion, respectively, along with the ions at $m / z 247\left(265-\mathrm{H}_{2} \mathrm{O}\right)$ and $221\left(239-\mathrm{H}_{2} \mathrm{O}\right)$. The ions at $m / z 265$ and 247 are more abundant than the ions at $\mathrm{m} / \mathrm{z} 239$ and 221, respectively, reflecting that the 18:1- and 16:0-fatty acid substituents are located at $s n-2$ and $s n-1$ of the glycerol backbone [13]. This is also consistent with findings that the ions at $\mathrm{m} / \mathrm{z} 265$ and 247 are respectively more prominent than the ions at $\mathrm{m} / z 267$ (18:0-acylium ion) and 249 (267 $\mathrm{H}_{2} \mathrm{O}$ ) in the $\mathrm{MS}^{3}$ spectrum of the ion at $m / z 605(867 \rightarrow$ 605 , Figure 1f), signifying that the 18:1-fatty acid substituent is located at $s n-2$, while the 18:0-fatty acid substituent is located at $s n-3$, representing a outer fatty acid substituent. This difference in the abundances of the acylium ions in the $\mathrm{MS}^{3}$ spectrum of $[\mathrm{M}+\mathrm{Li}-$ $\left.\mathrm{R}_{n} \mathrm{CO}_{2} \mathrm{Li}\right]^{+}$ions is readily applicable for confirmation of the fatty acid substituents on the glycerol backbone.

The ions at $m / z 521$ (577-56) and 503 (577-74) (Figure 1e) also arise from various cleavages of the glycerol backbone involving rearrangements [14, 15]. The proposed structure of the ion at $\mathrm{m} / \mathrm{z} 503$ is further supported by its MS ${ }^{4}$ spectrum $(867 \rightarrow 577 \rightarrow 503$; data not shown), which contains ions at $\mathrm{m} / \mathrm{z} 485,307$ and 265 (Scheme 2). Similar losses of the glycerol residues were also seen for the ion at $m / z 605$ (Figure 1f), which arises from loss of the outer fatty acid; but the analogous losses were not seen in the $\mathrm{MS}^{3}$ spectrum of the ions of $\mathrm{m} / \mathrm{z} 579$ (data not shown), a $\left[\mathrm{M}+\mathrm{Li}-\mathrm{R}_{2} \mathrm{CO}_{2} \mathrm{Li}\right]^{+}$ arising from loss of inner fatty acid. These internal losses of glycerol residues are further confirmed by observation of the fragment ions that correspond to losses of 60 and $79 \mathrm{Da}$ in the $\mathrm{MS}^{3}$ spectrum of the analogous $\left[\mathrm{M}+\mathrm{Li}-\mathrm{R}_{n} \mathrm{CO}_{2} \mathrm{Li}\right]^{+}$ions arising from $d_{5}-17: 0 / 17: 1 / 17: 0-T A G$ in which the glycerol hydrogen atoms are substituted by deuterium atoms (see Figure $5 \mathrm{~b}$ and the discussion therein). The ion at $\mathrm{m} / \mathrm{z} 321$ (577-256) from further loss of 16:0-fatty acid substituent at $s n-1$ is more abundant than the ion at $\mathrm{m} / \mathrm{z} 313$ (577-282), arising from further loss of 18:1-fatty acid substituent at $s n-2$. This differential loss of the fatty acid substituents dependent on the position of the fatty acid substituents on the glycerol backbone also applicable in the confirmation of the location of fatty acid substituents.

The IT MS ${ }^{2}$ spectrum of the $\left[\mathrm{M}+\mathrm{Li}^{+}\right.$ion of the 16:0/18:0/18:1-TAG regioisomer at $m / z 867$ (Figure 2a), again, is dominated by the ions at $m / z 611,585$ and 583 , arising from losses of the 16:0-, 18:1- and 18:0-fatty acid substituents at $s n-1, s n-3$, and $s n-2$, respectively. The former two ions are nearly of equal abundance and are more abundant than the ion at $\mathrm{m} / \mathrm{z} 583$, suggesting that the 18:0-FA is located at $s n-2$. The results are consistent with the finding that the ions at $\mathrm{m} / \mathrm{z} 605$ and 579 , arising from losses of the 16:0-, 18:1-FA moieties at $s n-1$ and $s n-3$ as lithium salt are more abundant than the ion at $\mathrm{m} / \mathrm{z} 577$, arising from loss of the 18:0-FA acid substituent at $s n-2$ as a lithium salt.

The position of double bond of the 18:1-FA substituent at $s n-3$ is revealed by further dissociation of the ions at $m / z 611(867 \rightarrow 611$, Figure $2 b)$ and at $m / z 583(867 \rightarrow$ 583, Figure 2c). The former spectrum contains ions at $\mathrm{m} / \mathrm{z} 513,457,471$, and 415 (Figure 2b, inset), identical to those seen in Figure 1b, along with the ion at $m / z 401$ from $\beta$-cleavage ( $\beta$ to the carbonyl group) (Scheme 1c) indicating that the double bond is located at $C(9)$. The latter spectrum contains ions at $\mathrm{m} / \mathrm{z} 485,429,443,387$,
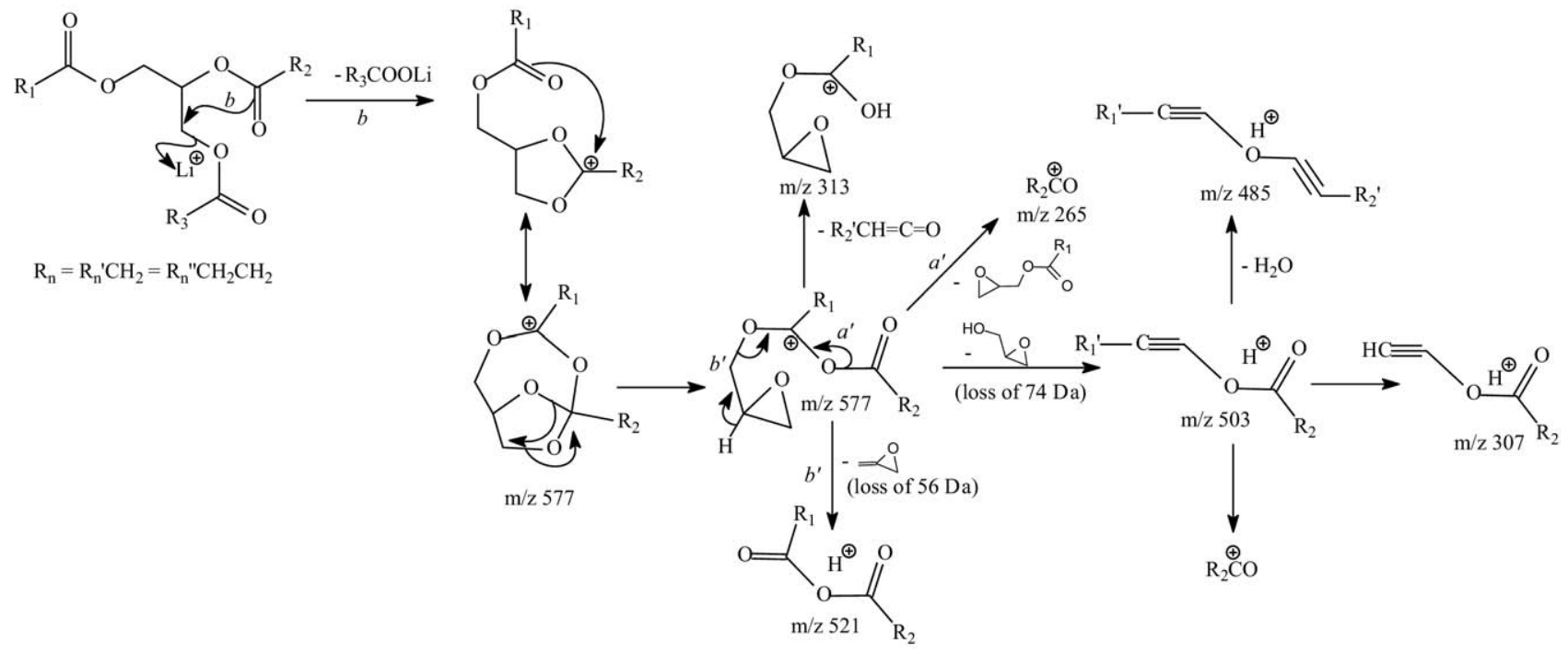

Scheme 2. The fragmentation processes proposed for losses of various glycerol residues for the $[\mathrm{M}+$ Alk $\left.-\mathrm{R}_{\mathrm{n}} \mathrm{CO}_{2} \mathrm{Alk}\right]^{+}$ions (Alk $\left.=\mathrm{Li}, \mathrm{Na}, \mathrm{NH} 4, n=1,3\right)$. The $m / z$ values shown represent the ions seen for the $[\mathrm{M}+\mathrm{Li}]^{+}$ions of 16:0/18:1/18:0-TAG. The pathways were supported by the analogous spectrum of $\mathrm{d}_{5}-17: 0 / 17: 1 / 17: 0-\mathrm{TAG}$ in which the hydrogen atoms $(\mathrm{C}-\mathrm{H})$ of the glycerol backbone were replaced by deuterium atoms. 

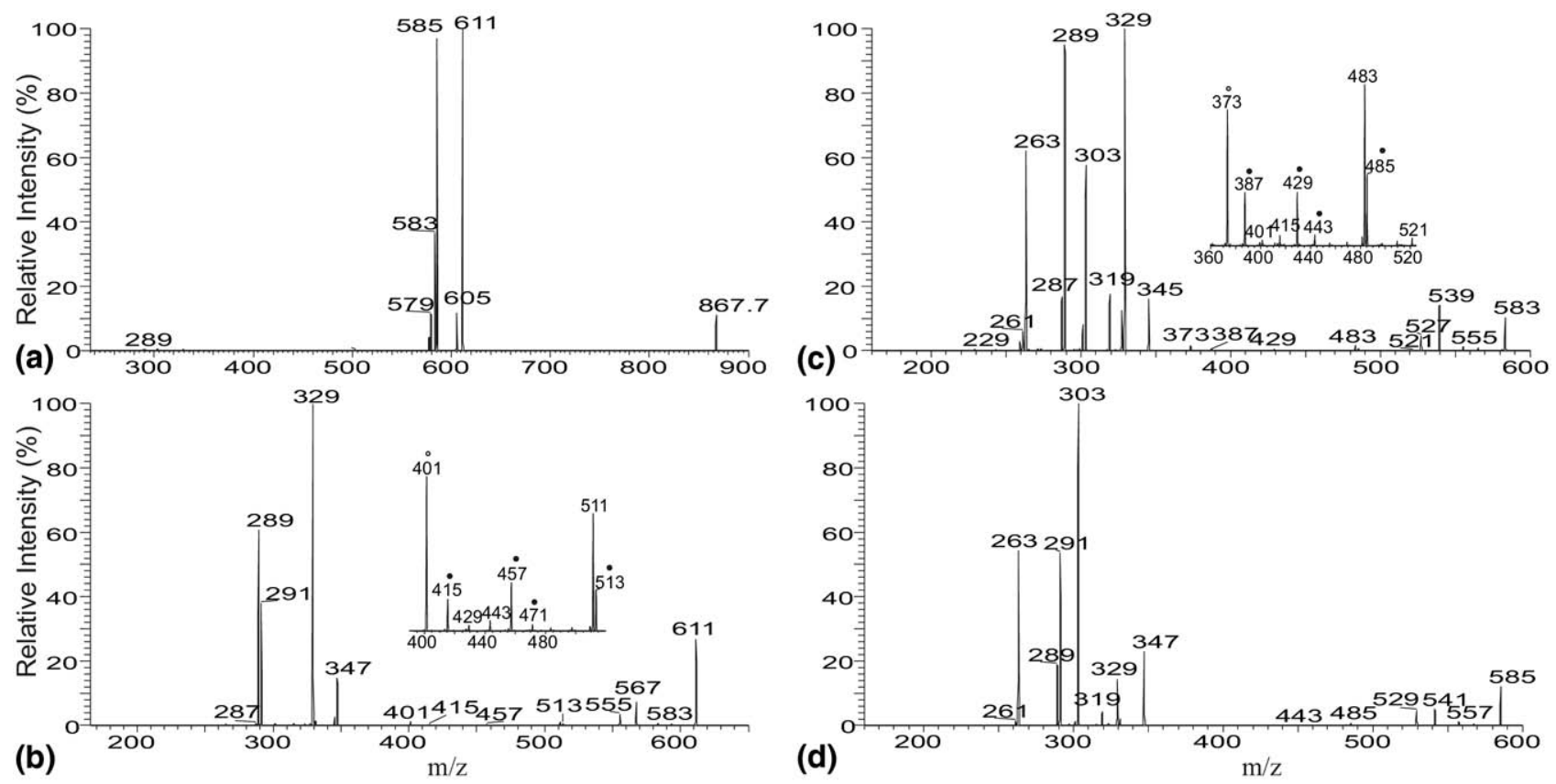

Figure 2. The LIT MS ${ }^{2}$ spectrum of the $[\mathrm{M}+\mathrm{Li}]^{+}$ion of the $16: 0 / 18: 0 / 18: 1-\mathrm{TAG}$ at $\mathrm{m} / \mathrm{z} 867$ (a), its MS $^{3}$ spectra of the ions at $\mathrm{m} / z 611(867 \rightarrow 611)(\mathbf{b})$, at $\mathrm{m} / \mathrm{z} 583(867 \rightarrow 583)(\mathbf{c})$, and at $\mathrm{m} / \mathrm{z} 585(867 \rightarrow$ $585)$ (d). In the subsets (panel b and c), the ions labeled with filled circle identified the position of double bond(s).

and 373 (Figure 2c, inset), which are identical to those seen in Figure 1c, reflecting that the double bond is located at C(9). The IT MS ${ }^{3}$ spectrum of the ion at $\mathrm{m} / \mathrm{z}$ $585(867 \rightarrow 585$, Figure $2 \mathrm{~d})$ is dominated by the ion at $\mathrm{m} / \mathrm{z} 303$, corresponding to loss of an 18:1-fatty acid residue, in agreement with the earlier finding that the 18:0-fatty acyl group at $s n-2$ was further eliminated as an $\alpha, \beta$-unsaturated fatty acid.

\section{Structural Characterization of $A / B / A-T A G$ and $A / A / B$ (or $B / A / A$ )-TAG Regioisomers}

Both the LIT MS ${ }^{2}$ spectra of the lithiated ions of 16:0/ 18:1/16:0-TAG (Figure 3a) and 18:1/16:0/16:0-TAG (Figure 3d) at $m / z 839$ are dominated by the ion at $\mathrm{m} / \mathrm{z}$ 583 , arising from loss of 16:0-FA moiety. The ion at $\mathrm{m} / \mathrm{z}$ 557 arising from loss of 18:1-FA is abundant in Figure $3 \mathrm{~d}$, but is of low abundance in Figure 3a. This is consistent with the fact that the 18:1/16:0/16:0-TAG contains a 18:1-FA at $s n-1$, while the 16:0/18:1/16:0TAG (Figure 3a) contains a 18:1-FA at sn-2. The LIT MS ${ }^{3}$ spectrum of the ion at $m / z 557(839 \rightarrow 557$, Figure $3 \mathrm{~b}$ ) originated from 16:0/18:1/16:0-TAG is identical to that originated from 18:1/16:0/16:0-TAG (Figure 3e). This is consistent with the notion that the loss of the fatty acid substituents involves the participation of the $\alpha$-hydrogen of the neighboring fatty acid substituent, resulting in an identical 5-member intermediate, which further eliminates the 16:0-FA as an $\alpha, \beta$-unsaturated fatty acid (loss as 16:1-FA) to yield the prominent ion at $\mathrm{m} / \mathrm{z} 303$. The LIT MS ${ }^{3}$ spectrum of the ion at $m / z 583(839 \rightarrow 583$, Figure 3c) contains the prominent ion at $\mathrm{m} / \mathrm{z} 303$ arising from elimination of the 18:1-FA at $s n-2$ as an $\alpha, \beta-$ unsaturated fatty acid (loss as 18:2-FA); while the LIT $\mathrm{MS}^{3}$ spectrum of the ion at $m / z 557(839 \rightarrow 557$, Figure 3e) originated from 18:1/16:0/16:0-TAG isomer is dominated by the ion at $m / z 303$, arising from loss of the 16:0-fatty acid at $s n-2$ as an $\alpha, \beta$-unsaturated fatty acid (loss as 16:1). The results confirm that the former molecule contains 18:1-fatty acid at $s n-2$; whereas the latter TAG consists of a 16:0-fatty acid substituent at $s n-2$. In Figure 3c (subset), the ions at $m / z$ 485, 429, 443, 387 , and 373 that identify the position of double bond of the 18:1-fatty acid residue are also present, leading to assignment of the double bond at C(9). The set of ions of $m / z 485,429,443,387$, and 373 were also seen in Figure 3f (subset), revealing that the double bond of the 18:1-FA substituent is also located at C(9).

The profiles of the LIT MS ${ }^{2}$ spectrum of 18:1/18:0/18: 0-TAG (see supplemental material, which can be found in the electronic version of this article, Figure S1a) and of the MS $^{3}$ spectra of the ions at $\mathrm{m} / \mathrm{z} 613$ (Figure $\mathrm{S} 1 \mathrm{~b}$ ) and at $\mathrm{m} / \mathrm{z} 611$ (Figure S1c) are identical to those seen in Figure 3d, e, and $\mathrm{f}$, respectively, in agreement with the notion that both the 18:1/16:0/16:0-TAG and 18:1/18:0/18:0-TAG belong to the B/A/A (or A/A/B) class. The profiles of the $\mathrm{MS}^{n}(n=2,3)$ spectra from 18:0/18:1/18:0-TAG (data not shown) are also identical to those seen for 16:0/18:1/16:0-TAG (Figure 3a-c), indicating that they all belong to the $\mathrm{A} / \mathrm{B} / \mathrm{A}$ subclass. The distinction in the $\mathrm{MS}^{n}$ spectra (Figure 3a versus Figure $3 d$; Figure $3 c$ versus $3 f$ ) between the TAG isomers of $\mathrm{A} / \mathrm{B} / \mathrm{A}$ and $\mathrm{A} / \mathrm{A} / \mathrm{B}$ classes are substantial, leading to differentiation of isomers by mass spectrometry. 

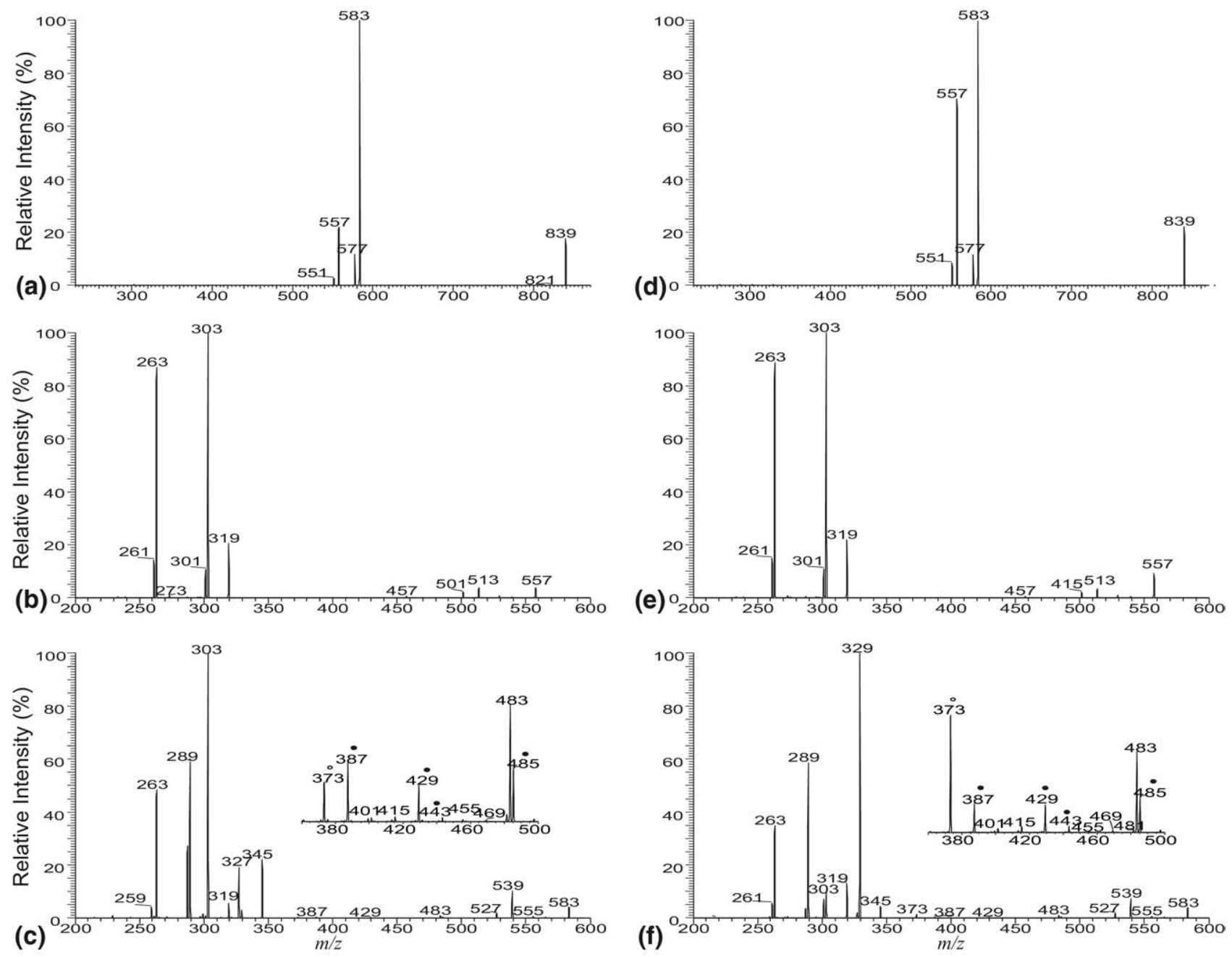

Figure 3. The LIT MS ${ }^{2}$ spectrum of the $[\mathrm{M}+\mathrm{Li}]^{+}$ions of 16:0/18:1/16:0-TAG at $m / z 839$ (a), its MS ${ }^{3}$ spectra of the ions at $m / z 557(839 \rightarrow 557)(\mathbf{b})$, and at $m / z 583(839 \rightarrow 583)(\mathbf{c})$, and the LIT MS ${ }^{2}$ spectrum of the $[\mathrm{M}+\mathrm{Li}]^{+}$ions of 18:1/16:0/16:0-TAG at $m / z 839(\mathbf{d})$, its $\mathrm{MS}^{3}$ spectra of the ions at $\mathrm{m} / \mathrm{z} 557(839 \rightarrow$ $557)(\mathbf{e})$, and at $m / z 583(839 \rightarrow 583)(\mathbf{f})$. In the subsets (panel c and f), the ions labeled with filled circle identified the position of double bond(s).

\section{Characterization of TAG Consisting of Polyunsaturated Fatty Acid Moieties}

The $\mathrm{MS}^{2}$ spectrum of the $[\mathrm{M}+\mathrm{Li}]^{+}$ion of 20:4/20:4/ 20:4-TAG at $m / z 957$ (Figure $4 a$ ) is dominated by the ion at $\mathrm{m} / \mathrm{z}$ 653, arising from loss of the 20:4-fatty acid substituent. By contrast, the ion at $m / z 647$ arising from loss of the 20:4-fatty acid as a lithium salt is of low abundance. Further dissociation of the ion at $\mathrm{m} / \mathrm{z} 653$ $(957 \rightarrow 653$, Figure $4 b$ ) gives rise to the ion at $m / z 351$, by elimination of the 20:4-fatty acid moiety as an $\alpha, \beta$ unsaturated fatty acid (loss as 20:5 fatty acid) as described earlier. The spectrum also contains two ion series at $m / z 555,515$, and 475 and at $m / z 503$ and 463, indicating the presence of the homoconjugated double bonds at C(5), C (8), C(11), and C(14) (Scheme 3a). These ions are analogous to the ions at $\mathrm{m} / \mathrm{z} 219,179,139,167$, and 127 that were previously observed for locating the double bonds for $\Delta^{5,8,11,14}-20: 4$ fatty acid using LIT MS ${ }^{2}$ on the dilithiated adduct ions [12].
The ion at $m / z 609$ (Figure $4 \mathrm{~b}$ ) may arise from loss of a $\mathrm{CO}_{2}$ residue. Further dissociation of the ion at $m / z 609$ (957 $\rightarrow 653 \rightarrow 609$, Figure 4c) also gives rise to the ion at $m / z$ 553 , arising from loss of a [glycerol $-2 \mathrm{H}_{2} \mathrm{O}$ ] residue as described earlier. The spectrum also contains two sets of ions at $m / z 511,471,431$, and at $m / z 459$ and 419. These ions are analogous to those seen in Figure $4 \mathrm{~b}$, and are $44 \mathrm{Da}$ lighter, consistent with the fact that the precursor ion at $\mathrm{m} / \mathrm{z} 609$ arises from loss of a 44 Da residue from $\mathrm{m} / \mathrm{z} 653$. The results further support the assignment of the position of double bonds of the 20:4-fatty acid substituents. The $\mathrm{MS}^{4}$ spectrum of the ion at $m / z 553(957 \rightarrow 653 \rightarrow 553$, data not shown) contains two ion series at $m / z 455,415,375$, and at $m / z 403,363$; and the $\mathrm{MS}^{4}$ spectrum of the ion at $\mathrm{m} / \mathrm{z}$ 351 (957 $\rightarrow 653 \rightarrow 351$, Figure $4 d$ ) also contains two ion series at $m / z 253,213$, and 173, and at $m / z$ 201, 161 (Scheme $3 \mathbf{b})$. The observation of these ions, again, is consistent with the assignment of the position of double bonds along the 20:4-fatty acyl chain (Scheme 3). 

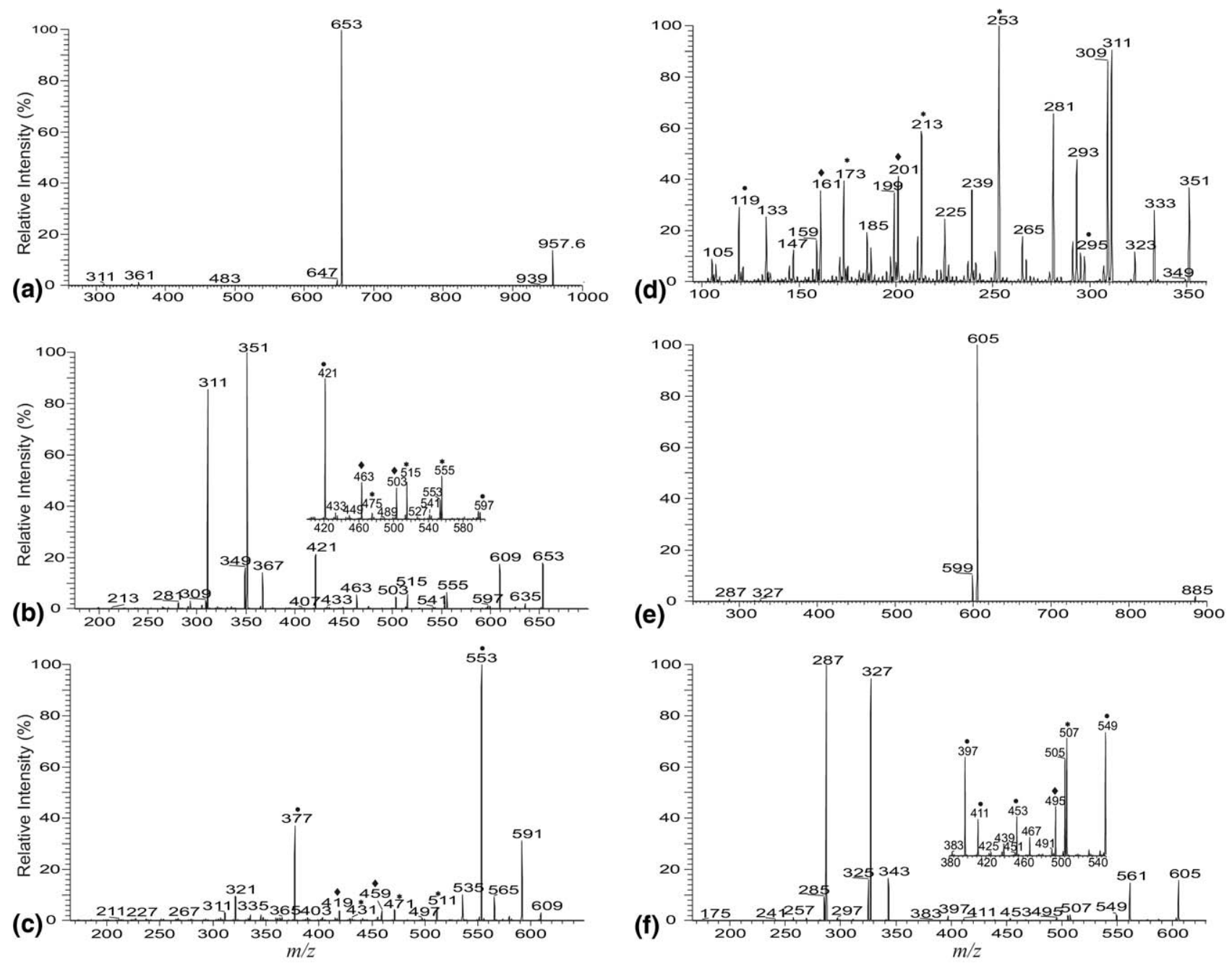

Figure 4. The LIT MS ${ }^{2}$ spectrum of the $\left[\mathrm{M}+\mathrm{Li}^{+}\right.$ions of 20:4/20:4/20:4-TAG at $m / z$ $957(\mathbf{a})$, its $\mathrm{MS}^{3}$ spectrum of the ions at $m / z 653(957 \rightarrow 653)(\mathbf{b})$, and its MS ${ }^{4}$ spectra of the ions at $m / z 609(957 \rightarrow 653$ $\rightarrow 609)(\mathrm{c})$, and at $\mathrm{m} / \mathrm{z} 351(957 \rightarrow 653 \rightarrow 351)$. The LIT MS ${ }^{2}$ spectrum of the $[\mathrm{M}+\mathrm{Li}]^{+}$ions of 18:2/18:2/18:2-TAG at $m / z 885(\mathbf{e})$, and its $\mathrm{MS}^{3}$ spectrum of the ions at $m / z 605(885 \rightarrow 605)(\mathbf{f})$ are also shown. In panels $\mathrm{c}$ and $\mathrm{d}$, and in the subsets (panel $\mathrm{b}$ and $\mathrm{f}$ ), the ions labeled with a filled diamond (vinyl cleavage), asterisk (allylic cleavage), and filled circle ( $\beta$-cleavage) are feature ions that identify the position of the double bonds of the 20:4-fatty acid moiety (see Scheme 3).

The LIT $\mathrm{MS}^{2}$ spectrum of the $\left[\mathrm{M}+\mathrm{Li}^{+}\right.$ion of 18:2/18:2/18:2-TAG at $m / z 885$ (Figure $4 \mathrm{~d}$ ) is dominated by the ion at $m / z 605$, arising from loss of the 18:2-fatty acid, along with the ion at $m / z 599$, arising from loss of 18:2-fatty acid as a lithium salt. The LIT MS ${ }^{3}$ spectrum of the ion at $m / z 605(885 \rightarrow 605$, Figure $4 \mathrm{f})$ contains the prominent ion at $m / z 327$ (605-278), from further elimination of the 18:2-fatty acid as an $\alpha, \beta$-unsaturated fatty acid (loss as 18:3 fatty acid). The position of the double bond of 18:2-fatty acid is seen by the ions at $\mathrm{m} / \mathrm{z} 549$ and 453 (Figure 4f, subset), arising from CRF cleavages of $C(7)-C(8)$ and $C(14)-C(15)$ bonds with McLafferty rearrangements, along with ions at $\mathrm{m} / \mathrm{z} 507$ and 495, arising from $\alpha$-cleavage with allylic hydrogen shift (see supplemental material Scheme 1). These ions are analogous to those previously observed in the $\mathrm{MS}^{2}$ spectrum of the dilithiated ion of $\Delta^{9,12}-18: 2$ [12], leading to locate the double bonds of the 18:2-fatty acyl groups at $\mathrm{C}(9)$ and $\mathrm{C}(12)$.

The Fragmentation Pathways Supported by LIT MS ${ }^{n}$ on 1,3(d $\left.d_{5}\right)$-Diheptadecanoyl-2-(10Z-Heptadecenoyl)Glycerol $\left[d_{5^{-}}\left(17: 0 / \Delta^{10} 17: 1 / 17: 0\right)-T A G\right]$

The profile of the LIT MS ${ }^{2}$ spectrum of the $[\mathrm{M}+\mathrm{Li}]^{+}$ ion of $\left[\mathrm{d}_{5^{-}}\left(17: 0 / \Delta^{10} 17: 1 / 17: 0\right)-T A G\right]$ at $\mathrm{m} / \mathrm{z} 858$ (Figure $5 a)$ is similar to that shown in Figure $3 a$, arising from an A/B/A TAG subclass. The ions at $\mathrm{m} / \mathrm{z} 588$ (858 $\left.\mathrm{C}_{16} \mathrm{H}_{33} \mathrm{CO}_{2} \mathrm{H}\right)$ and $590\left(858-\mathrm{C}_{16} \mathrm{H}_{31} \mathrm{CO}_{2} \mathrm{H}\right)$ arise from losses of the 17:0- and 17:1-fatty acid substituents, and the ions at $m / z 582$ and 584 arise from losses of the 17:0and 17:1-fatty acid substituents as lithium salt, respectively. The observation of the losses of the $\mathrm{C}_{16} \mathrm{H}_{33} \mathrm{CO}_{2} \mathrm{H}$ 

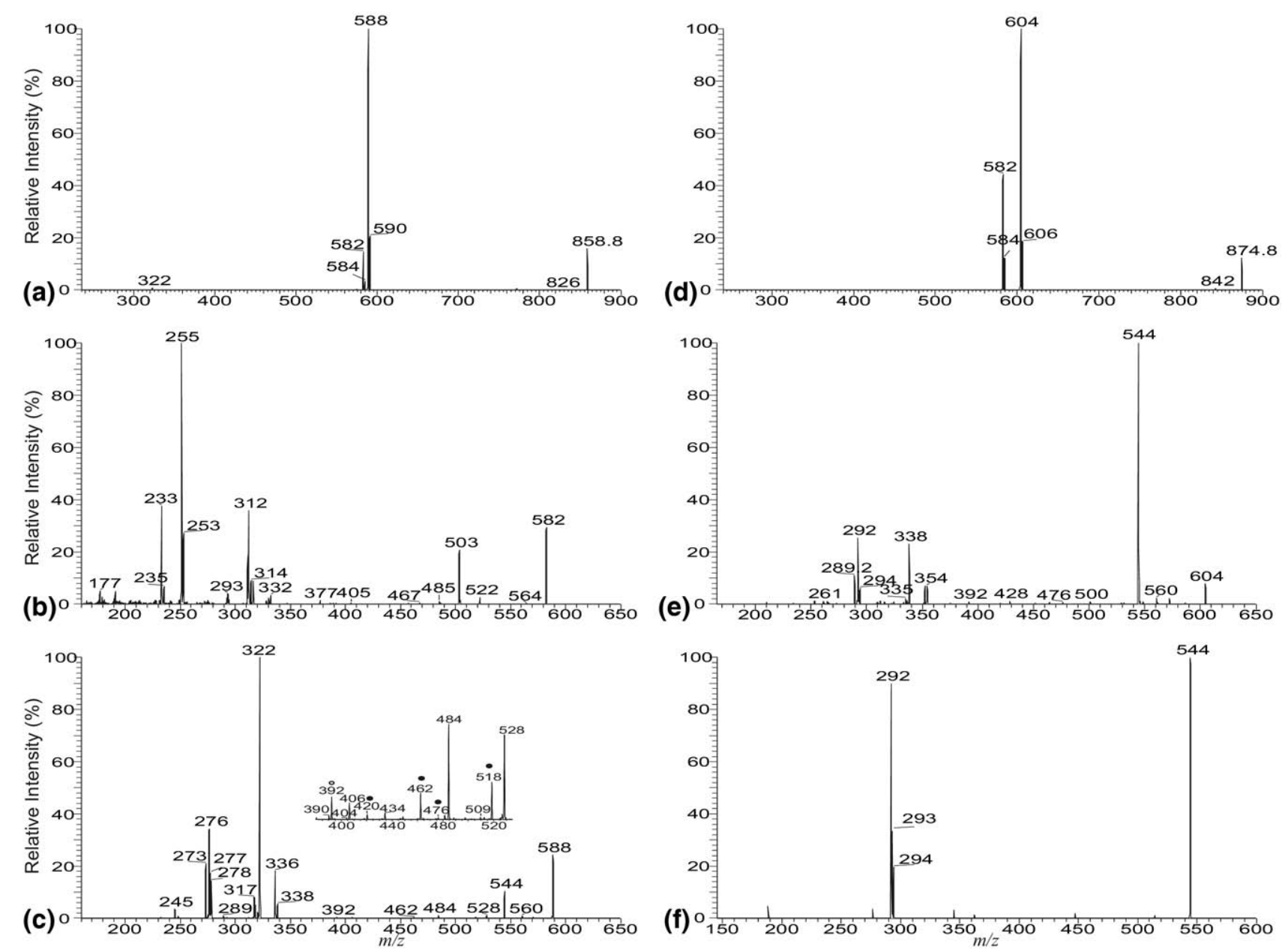

Figure 5. The LIT MS ${ }^{2}$ spectrum of the $[\mathrm{M}+\mathrm{Li}]^{+}$ions of $\mathrm{d}_{5}-17: 0 / 17: 1 / 17: 0-\mathrm{TAG}$ at $\mathrm{m} / \mathrm{z} 858(\mathbf{a})$, and its $\mathrm{MS}^{3}$ spectra of the ions at $m / z 582(858 \rightarrow 582)(\mathbf{b})$, and at $m / z 588(858 \rightarrow 588)(\mathbf{c})$. The LIT MS ${ }^{2}$ spectrum of the $[\mathrm{M}+\mathrm{Na}]^{+}$ions of $\mathrm{d}_{5}-17: 0 / 17: 1 / 17: 0-\mathrm{TAG}$ at $m / z 874(\mathbf{d})$, its $\mathrm{MS}^{3}$ spectrum of the ions at $m / z 604(874 \rightarrow 604)(\mathbf{e})$ and its $\mathrm{MS}^{4}$ spectrum of the ion at $\mathrm{m} / z 544(874 \rightarrow 604 \rightarrow 544)(\mathbf{f})$. In the subset (panel c), the ions labeled with filled circle identified the position of double bond(s).

and $\mathrm{C}_{16} \mathrm{H}_{31} \mathrm{CO}_{2} \mathrm{H}$ residues rather than losses of the $\mathrm{C}_{16} \mathrm{H}_{33} \mathrm{CO}_{2} \mathrm{D}$ and $\mathrm{C}_{16} \mathrm{H}_{31} \mathrm{CO}_{2} \mathrm{D}$ residues indicates that the elimination of the acid residues does not involve the participation of the hydrogen atom on the glycerol backbone. This is consistent with the proposed mechanisms in which the pathways leading to the fatty acid losses involve the participation of the $\alpha$-hydrogen of the neighboring fatty acyl moiety (Scheme 1) [4]. The MS ${ }^{3}$ spectrum of the ion of $m / z 582(858 \rightarrow 582$, Figure $5 \mathrm{~b})$ contains the ions at $m / z 522$ (loss of $\mathrm{C}_{3} \mathrm{D}_{4} \mathrm{O}$ ), 503 (loss of $\mathrm{C}_{3} \mathrm{HD}_{5} \mathrm{O}_{2}$ ), and 485 (loss of $\mathrm{C}_{3} \mathrm{H}_{3} \mathrm{D}_{5} \mathrm{O}_{3}$ ), of which the mass shifts match the proposed structures (Scheme 4) and support the earlier findings of the various internal losses of the glycerol residues.

Further dissociation of the ion of $m / z 588(858 \rightarrow 588$, Figure 5c) yielded ions at $m / z 518$ and 462 (Figure $5 c$, inset), arising from $\beta$-cleavage with $\gamma-\mathrm{H}$ shift fragmentations. These ions together with ions at $\mathrm{m} / \mathrm{z} 420,406$ and 392 demonstrate that the double bond of the 17:1-fatty acid substituent at $s n-2$ is located at $C(10)$, consistent with the notion that the molecule is a $d_{5}-(17$ : $\left.0 / \Delta^{10} 17: 1 / 17: 0\right)$-TAG. The spectrum is dominated by the ion at $m / z 322$, arising from loss of the 17:1-fatty acyl group as an $\alpha, \beta$-unsaturated fatty acid (loss as 17:2-fatty acid), along with ion at $m / z 273$, representing a lithiated 17:2-fatty acid cation. The observation of these ions along with the ions at $\mathrm{m} / \mathrm{z} 336$ arising from loss of 17:0-fatty acid as a ketene and at $\mathrm{m} / \mathrm{z} 317$ arising from loss of $\mathrm{d}_{1}$-17:0-fatty acid (loss as $\mathrm{C}_{16} \mathrm{H}_{33} \mathrm{CO}_{2} \mathrm{D}$ ) supports the proposed mechanism depicted in Scheme 1a.

\section{LIT $M S^{n}$ Spectra of the $[M+N a]^{+}$and $\left[\mathrm{M}+\mathrm{NH}_{4}\right]^{+}$Ions of TAG}

The LIT MS ${ }^{2}$ spectrum of the $[\mathrm{M}+\mathrm{Na}]^{+}$ions of TAG is similar to that arising from the $\left[\mathrm{M}+\mathrm{Li}^{+}\right.$ions and is readily applicable for assignment of the fatty acyl substituents on the glycerol backbone. The product-ion spectrum of the sodiated (16:0/18:1/18:0)-TAG at $\mathrm{m} / \mathrm{z}$ 883 (Figure 6a) contains the ions at $\mathrm{m} / \mathrm{z} 627$ and 599 arising from losses of the outer 16:0- and 18:0-fatty acids 
(a)

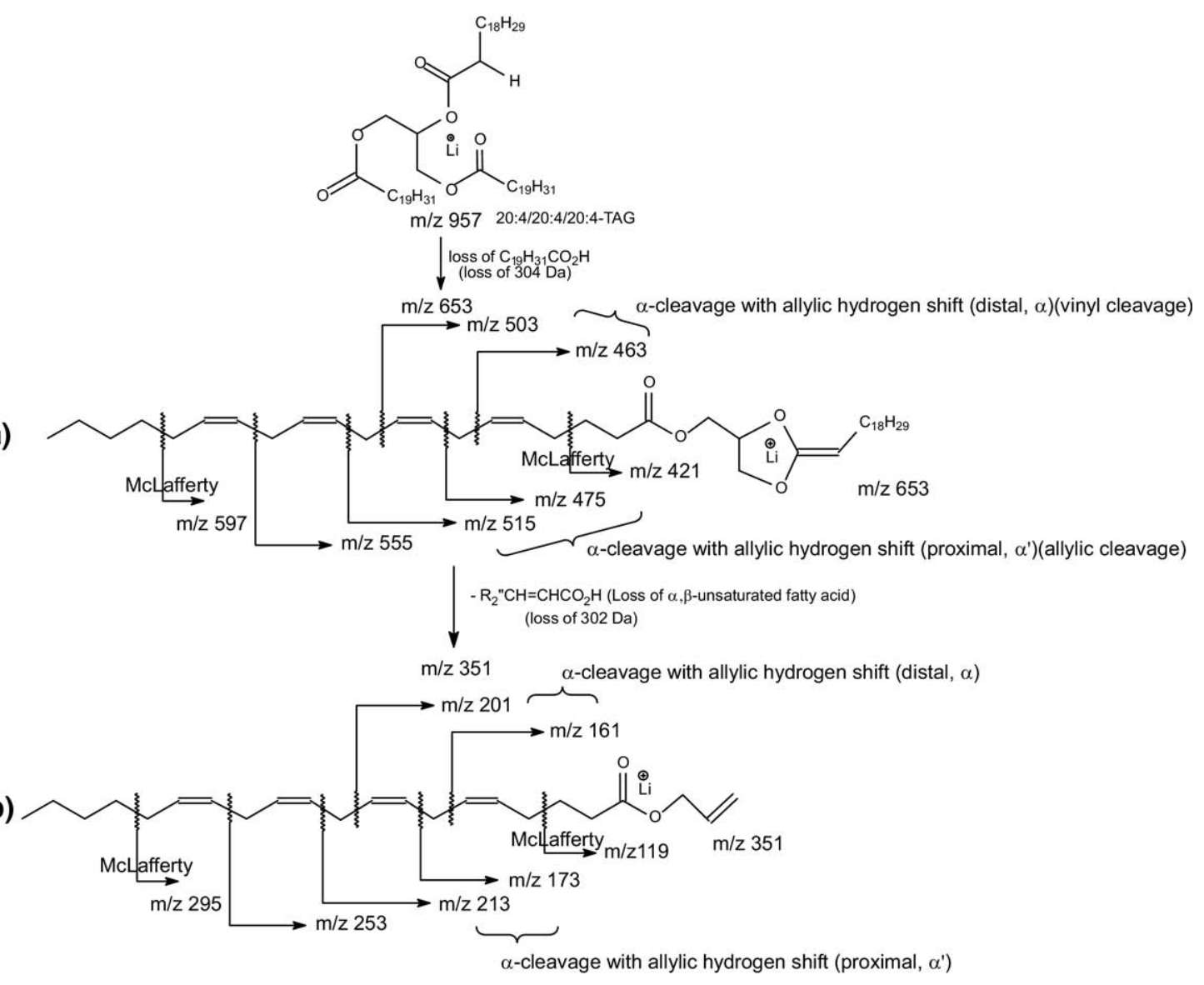

Scheme 3. The fragmentation pathways proposed for location of the double bonds along the fatty acid chain of 20:4/20:4/20:4-TAG from $\mathrm{MS}^{3}$ on the $\left[\mathrm{M}+\mathrm{Li}-\mathrm{R}_{3} \mathrm{CO}_{2} \mathrm{H}\right]$ ions (A), and from $\mathrm{MS}^{4}$ on the $\left[\mathrm{M}+\mathrm{Li}-\mathrm{R}_{3} \mathrm{CO}_{2} \mathrm{H}-\mathrm{R}_{2^{\prime \prime}} \mathrm{CH}=\mathrm{CHCO}_{2} \mathrm{H}\right]$ ions.

and the ion at $m / z 601$ arising from loss of the 18:1-fatty acid at $s n-2$. The ions at $\mathrm{m} / \mathrm{z} 627$ and 599 are more abundant than the ion at $\mathrm{m} / \mathrm{z} 601$. The ions at $\mathrm{m} / \mathrm{z} 605$ and 577 arising from losses of the outer 16:0- and 18:0-fatty acids as sodium salt (loss of $\mathrm{R}_{\mathrm{n}} \mathrm{CO}_{2} \mathrm{Na}$ ) are also more abundant than the ion at $\mathrm{m} / \mathrm{z} 579$, arising from the analogous loss of the 18:1 at $s n-2$. The results indicate that the 16:0- and 18:0-fatty acids are located at $s n-1$ and $s n-3$, respectively.

The ions at $m / z 605,577$, and 579 are more prominent than those seen in Figure 1a, indicating that the losses of fatty acids as sodium salts are more facile than the same losses as lithium salts. The ions corresponding to losses of the fatty acids as potassium salts become dominant in the $\mathrm{MS}^{2}$ spectrum of the corresponding $[\mathrm{M}+\mathrm{K}]^{+}$ions of TAG (data not shown). The ions at $\mathrm{m} / \mathrm{z} 605,577$, and 579 arising from losses of the fatty acid as ammonium salt become the exclusive ions in the $\mathrm{MS}^{2}$ spectrum of the $\left[\mathrm{M}+\mathrm{NH}_{4}\right]^{+}$ions of $(16: 0 / 18: 1 / 18: 0)-\mathrm{TAG}$ at $m / z 878$ (Figure $6 \mathrm{~d}$ ). The results indicate that the strength of metal and $\mathrm{NH}_{4}{ }^{+}$ions attached to TAG is in the order of $\mathrm{Li}^{+}>\mathrm{Na}^{+}>\mathrm{K}^{+}>\mathrm{NH}_{4}{ }^{+}$[16]. The $\mathrm{Li}^{+}$is localized on the $\left[\mathrm{M}+\mathrm{Li}-\mathrm{R}_{n} \mathrm{CO}_{2} \mathrm{H}\right]^{+}$ions remote from the fragmentation sites, resulting in the formation of the ion series informative for location of the double bonds; while the
$\mathrm{Na}^{+}, \mathrm{K}^{+}$, and $\mathrm{NH}_{4}{ }^{+}$on the sodiated, potassiated, and ammoniated precursor ions were lost before the CRF processes take place. The loss of metal ions is evidenced by observation of metal ions in the tandem quadrupole product-ion spectra of the $[\mathrm{M}+\mathrm{Na}]^{+}$ion at $m / z 881$ (see supplemental material Figure S2, panel a) and of the $[\mathrm{M}+\mathrm{K}]^{+}$ions at $\mathrm{m} / \mathrm{z} 897$ (panel b) of 16:0/18:0/18:1TAG, respectively. The former spectrum contained the ion at $m / z 23$, corresponding to the $\mathrm{Na}^{+}$ion, while the latter spectrum is dominated by the $\mathrm{K}^{+}$ion at $m / z 39$. The metal ion loss becomes even more prevalent, when $\mathrm{MS}^{2}$ on the $[\mathrm{M}+\mathrm{Cs}]^{+}$ions at $m / z 991$ with the same tandem quadrupole instrument was performed. The spectrum (see supplemental material Figure 2c), which was obtained with a much lower collision energy again, is dominated by the $\mathrm{Cs}^{+}$ion at $\mathrm{m} / \mathrm{z} 133$. However, these metal ions are not detectable using a LIT because of the low-mass cut-off nature of the instrument.

The $\mathrm{MS}^{3}$ spectrum of the ion at $m / z 627(883 \rightarrow 627$, Figure $6 \mathrm{~b})$ is dominated by the ion at $m / z 571(627-56)$, probably representing a sodiated ion of octadecanoyl octadecenoyl anhydride (18:0/18:1 acid anhydride) after removal of the glycerol residue from the ion of $\mathrm{m} / \mathrm{z}$ 627 (Scheme 4). This speculation is based on observation of the ions at $\mathrm{m} / \mathrm{z} 307$ and 305 representing the 


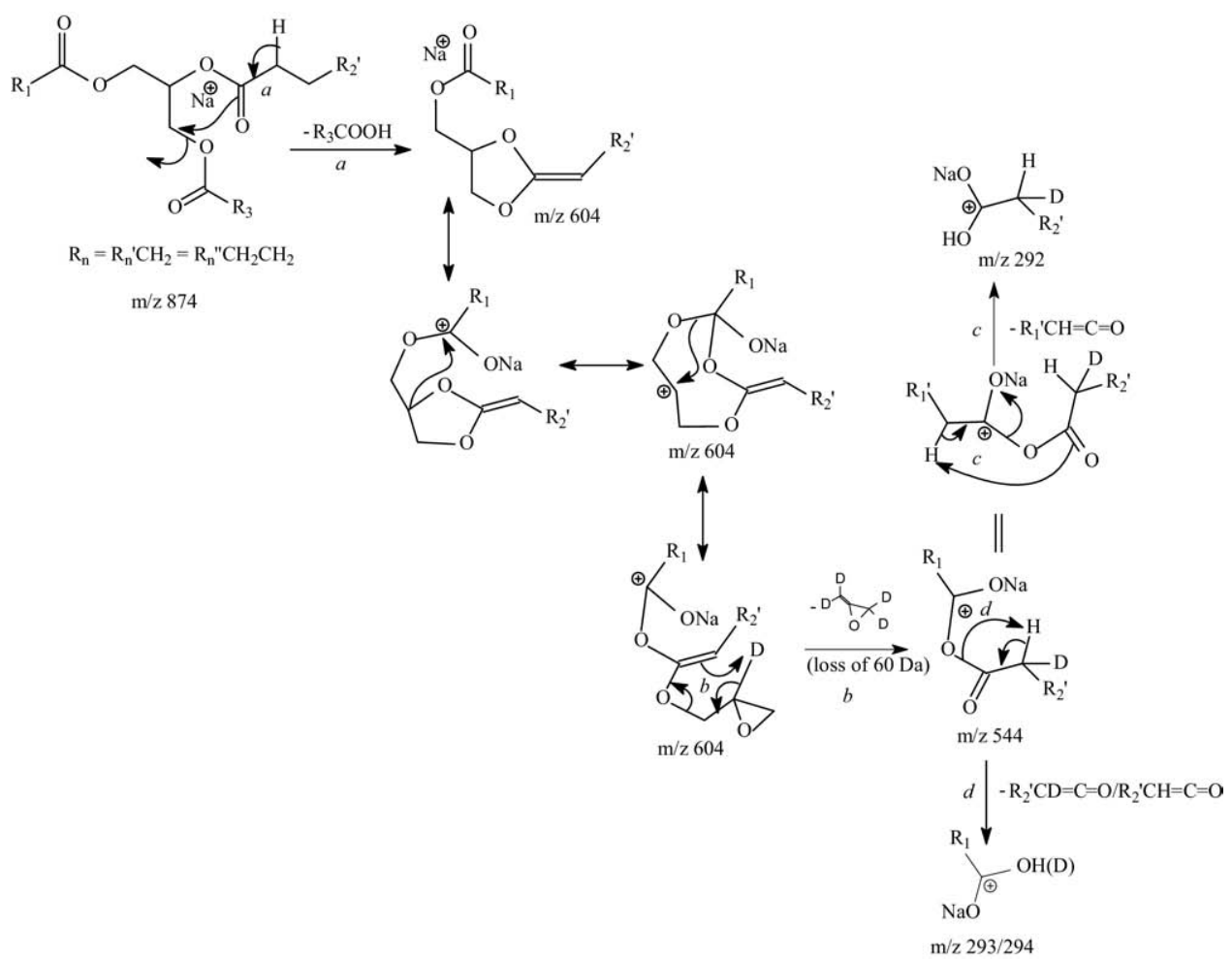

Scheme 4. The proposed fragmentation processes leading to internal loss of [glycerol $-2 \mathrm{H}_{2} \mathrm{O}$ ] (56 $\mathrm{Da}$ ) produced by $\mathrm{MS}^{n}$ on the $[\mathrm{M}+\mathrm{Na}]^{+}$ions of TAG. The $\mathrm{m} / z$ values shown in the scheme represent the observed mass seen for $d_{5}-17: 0 / 17: 1 / 17: 0-T A G$. The observation of loss of 60 Da (Figure $5 e$ ) supports the proposed internal loss of the glycerol residue. The internal loss was further supported by $\mathrm{MS}^{4}$ on the ion of $m / z$ 544, which gives ions at $m / z$ 292, 293, and 294 (see Figure 5f), deriving from the fragmentation processes as proposed.

sodiated ions of 18:0- and 18:1-fatty acids, respectively, in the $\mathrm{MS}^{4}$ spectrum of the ions at $\mathrm{m} / \mathrm{z} 571(883 \rightarrow 627 \rightarrow$ 571, Figure 6c) (Scheme 4). The ion series reflecting the location of double bond of the 18:1-fatty acid substituent at $s n-2$ as seen in Figure $1 \mathrm{~b}$ are absent in Figure $6 \mathrm{~b}$, attributable to the notion that the sodiated precursor ion is not stable and the internal energy of the precursor ion decomposed by CRF to yield the ions applicable for characterization is less than the energy required for releasing the $\mathrm{Na}^{+}$ion [16]. The $\mathrm{MS}^{3}$ spectra of the ions at $\mathrm{m} / \mathrm{z}$ 601 , and at 599 (data not shown) are also dominated by the ions at $\mathrm{m} / \mathrm{z} 545$ and 543, respectively, arising from further loss of $56 \mathrm{Da}$ (loss of [glycerol $-2 \mathrm{H}_{2} \mathrm{O}$ ]) and representing a 16:0/18:0 and a 16:0/18:1 fatty acid anhydride residues. This loss of 56 Da related to the glycerol backbone is supported by the $\mathrm{MS}^{3}$ spectrum of the analogous ion of $m / z 604(874 \rightarrow 604)$ (Figure 5e) arising from the $[\mathrm{M}+\mathrm{Na}]^{+}$ions of $\mathrm{d}_{5}-\left(17: 0 / \Delta^{10} 17: 1 /\right.$ 17:0)-TAG (Figure 5d). The spectrum (Figure 5e) is dominated by the ion at $\mathrm{m} / \mathrm{z} 544$, representing a sodiated ion of $d_{1}-17: 0 / 17: 1$ acid anhydride arising from the analogous loss of a $\mathrm{d}_{4}$-glycerol residue (Scheme 4), along with the ions at $m / z 338$ from loss of 17:1-fatty acid at $s n-2$ as a $\alpha, \beta$-unsaturated acid (loss as 17:2-FA) and the ion at $\mathrm{m} / \mathrm{z} 289$, representing a sodiated 17:2-fatty acid ion. The observation of the ions at $m / z 292,293$, and 294 arising from further losses of 17:0-, $\mathrm{d}_{1}-17: 1-$, and 17:1-fatty acyl ketene from $m / z 544$, respectively, in the $\mathrm{MS}^{4}$ spectrum of the ion of $\mathrm{m} / \mathrm{z} 544(874 \rightarrow 604 \rightarrow 544)$ (Figure 5f) is consistent with the formation of the sodiated $d_{1}-17: 0 / 17: 1$ acid anhydride ion by loss of the glycerol residue (loss of $60 \mathrm{Da}$ ) (Scheme 4). Similar losses of the glycerol residues were also observed in the MS $^{3}$ spectrum of the ion of $m / z 606(874 \rightarrow 606)$, which is dominated by the ion at $\mathrm{m} / \mathrm{z} 506$ (data not shown).

By contrast, the LIT MS ${ }^{2}$ spectrum of the $[\mathrm{M}+$ $\left.\mathrm{NH}_{4}\right]^{+}$ion of $(16: 0 / 18: 1 / 18: 0)-T A G$ at $m / z$ 878 (Figure $6 d$ ) contained ions at $m / z 605,577$, and 579 , arising from neutral losses of 16:0-, 18:0-, and 18:1-fatty acid substituents as ammonium salt (loss as $\mathrm{R}_{n} \mathrm{CO}_{2} \mathrm{NH}_{4}$ ), respectively (or the combined losses of the corresponding fatty acids and $\mathrm{NH}_{3}$ [17]), and the ions arising from losses of the fatty acid substituents were absent. The ions at $m / z 605$ and 577 are significantly more abundant than the ion at $m / z 579$. These preferential losses of the outer 16:0- and 18:0-fatty acid moieties as ammonium salt than the analogous loss of inner sn-2 18:1-fatty acid moiety are readily applicable for assignment of fatty acid substituents on the glycerol backbone.

The LIT MS ${ }^{3}$ spectrum of the ion at $m / z 605(878 \rightarrow$ 605 , Figure 6e) is nearly identical to that shown in Figure 1e, consistent with the notion that the 18:1- and 18:0-fatty acyl groups are located at $s n-2$ and $s n-3$, respectively. However, the ion at $m / z 341$ from further 

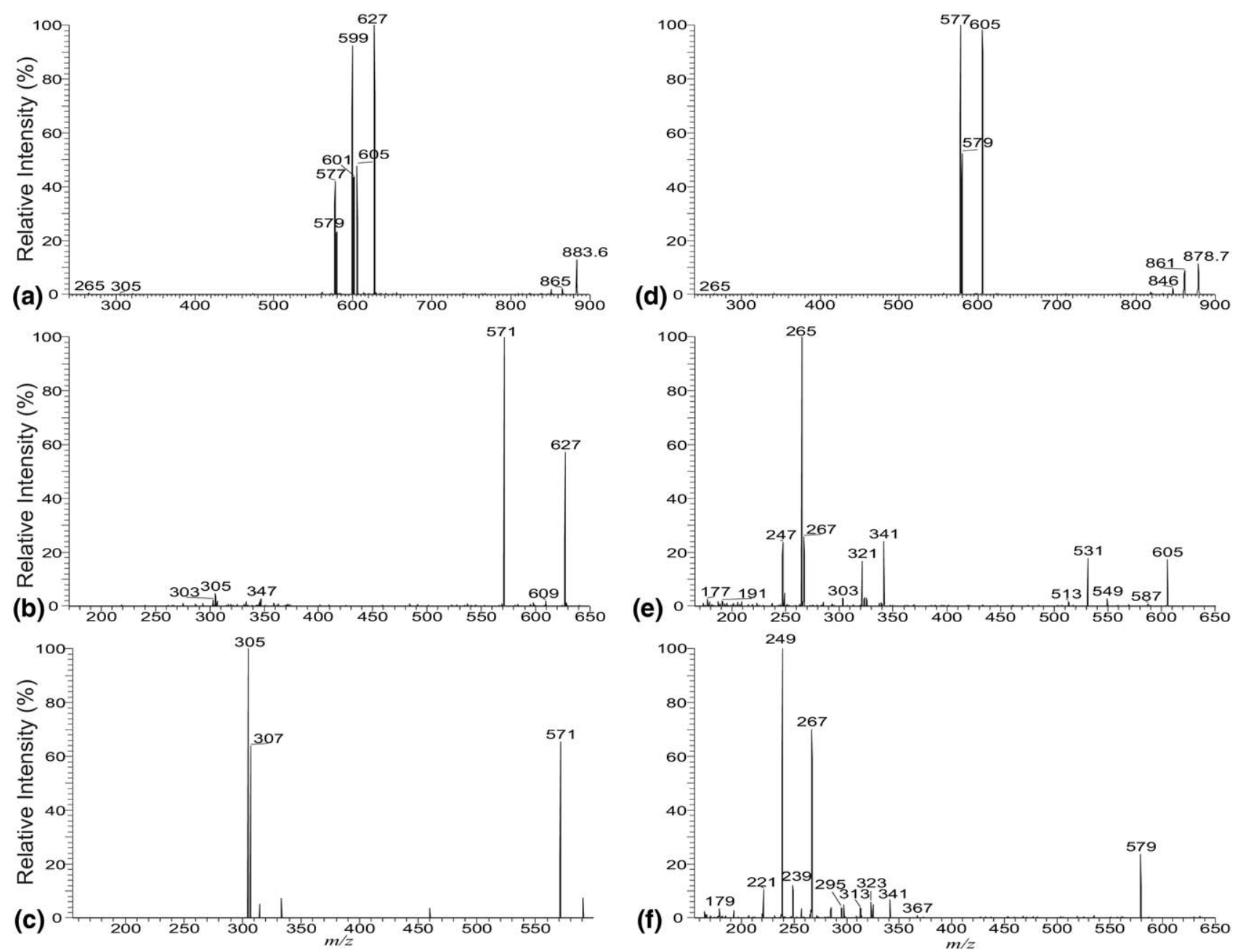

Figure 6. The LIT MS ${ }^{2}$ spectrum of the $[\mathrm{M}+\mathrm{Na}]^{+}$ions of 16:0/18:1/18:0-TAG at $m / z$ 863.6 (a), its MS $^{3}$ spectrum of the ions at $m / z 627(863 \rightarrow 627)(\mathbf{b})$, and its MS ${ }^{4}$ spectrum at $m / z 571(863 \rightarrow 627 \rightarrow$ 571) (c). The LIT MS ${ }^{2}$ spectrum of the $\left[\mathrm{M}+\mathrm{NH}_{4}\right]^{+}$ions of 16:0/18:1/18:0-TAG at $\mathrm{m} / z$ 878.7 (d), and its MS $^{3}$ spectra of the ions at $m / z 605(878 \rightarrow 605)(\mathbf{e})$, and at $m / z 579(878 \rightarrow 579)(\mathbf{f})$.

loss of 18:1-fatty acyl ketene (designated as $\left[\mathrm{RCO}^{+}+\right.$ $74]$ ion in references $[1,3,15])$ is more abundant than the similar ions seen in Figure 1, indicating that they may arise from different mechanisms [17]. The LIT MS ${ }^{3}$ spectrum of the ions at $\mathrm{m} / \mathrm{z} 577$ (data not shown) is similar to Figure 6e, consistent with the notion that both the ions of $\mathrm{m} / \mathrm{z} 605$ and 577 arise from loss of the outer fatty acid substituent. In contrast, the LIT MS ${ }^{3}$ spectrum of the ions at $m / z 579$ (Figure 6f), arising from loss of the fatty acid moiety at $s n-2$ is readily distinguishable from Figure 6e. The abundances of the ions at $m / z 341$ (loss of $s n-1$ fatty acyl ketene) and 323 (loss of $s n-1$ fatty acid) are close to those of the ions at $m / z 313$ (loss of $s n-3$ fatty acyl ketene) and 295 (loss of fatty acid at $s n-3$ ), respectively, in agree with the fact that they all retain the outer fatty acid moieties. The ions at $m / z 523,505$, and 487 arising from various losses of the glycerol residues are absent in the spectrum (Figure 6f) supporting the notion that the ion at $m / z 579$ arises from loss of the fatty acid group at $s n-2$ as described earlier. These spectra features dependent on the origin of precursor ions deriving from elimination of the fatty acid substituents at different positions (on the glycerol backbone) are readily applicable for confirmation of the assignment of the fatty acyl groups on the glycerol backbone.

The $\left[\mathrm{M}+\mathrm{NH}_{4}-\mathrm{R}_{n} \mathrm{CO}_{2} \mathrm{H}\right]^{+}$ions analogous to the $\left[\mathrm{M}+\mathrm{Li}-\mathrm{R}_{n} \mathrm{CO}_{2} \mathrm{H}\right]^{+}$ions are absent in the $\mathrm{MS}^{2}$ spectra (Figure 6d), thus, ions from $\mathrm{MS}^{3}$ on $\left[\mathrm{M}+\mathrm{NH}_{4}-\right.$ $\left.\mathrm{R}_{n} \mathrm{CO}_{2} \mathrm{H}\right]^{+}$for location of double bonds for the unsaturated fatty acid moieties as seen for the $[\mathrm{M}+\mathrm{Li}]^{+}$ions (i.e., ions from $\mathrm{MS}^{3}$ on the $\left[\mathrm{M}+\mathrm{Li}-\mathrm{R}_{n} \mathrm{CO}_{2} \mathrm{H}\right]^{+}$) are not available.

\section{Conclusions}

The employment of LIT MS ${ }^{n}$ on the $[\mathrm{M}+\mathrm{Li}]^{+}$ions of TAG desorbed by ESI affords near-complete structural characterization of TAG molecules, including the position of double bond(s) of the unsaturated fatty acyl moieties. The feature ions informative for location of the 
position of double bonds derived from further dissociation of the $\left[\mathrm{M}+\mathrm{Li}-\mathrm{R}_{n} \mathrm{CO}_{2} \mathrm{H}\right]^{+}$ions in an ion trap. However, these ions are not present in the $\mathrm{MS}^{3}$ spectra of $\left[\mathrm{M}+\mathrm{Na}-\mathrm{R}_{n} \mathrm{CO}_{2} \mathrm{H}\right]^{+}$or $\left[\mathrm{M}+\mathrm{NH}_{4}-\mathrm{R}_{n} \mathrm{CO}_{2} \mathrm{H}\right]^{+}$ ions and characterization of TAG by LIT MS ${ }^{n}$ on the [M + $\mathrm{Na}]^{+}$and $\left[\mathrm{M}+\mathrm{NH}_{4}\right]^{+}$ions is incomplete. Momchilova et al. demonstrated the separation of isobaric triacylglycerol positional isomers by reversed-phase highperformance liquid chromatography (RP-HPLC) [18]. Thus, this LIT MS ${ }^{n}$ with ESI approach coupled with RP-HPLC should have broad application in the characterization of TAGs, in particular, of biological origin which often consists of numerous isobaric species [17, 19] that are not separable by a mass spectrometer.

\section{Acknowledgments}

The authors acknowledge support for this research by U.S. Public Health Service grants P41-RR-00,954, R37-DK-34,388, P60-DK20,579, P01-HL-57,278, and P30-DK56341.

\section{Appendix A Supplementary Material}

Supplementary material associated with this article may be found in the online version at doi:10.1016/ j.jasms.2010.10.007

\section{References}

1. Cheng, C.; Gross, M. L.; Pittenauer, E. Complete Structural Elucidation of Triacylglycerols by Tandem Sector Mass Spectrometry. Anal. Chem. 1998, 70, 4417-4426.

2. Duffin, K. L.; Henion, J. D.; Shieh, J. J. Electrospray and Tandem Mass Spectrometric Characterization of Acylglycerol Mixtures That Are Dissolved in Nonpolar Solvents. Anal. Chem. 1991, 63, 1781-1788.

3. Pittenauer, E.; Allmaier, G. The Renaissance of High-Energy CID for Structural Elucidation of Complex Lipids: MALDI-TOF/RTOF-MS of Alkali Cationized Triacylglycerols. J. Am. Soc. Mass Spectrom. 2009, 20, 1037-1047.

4. Hsu, F.-F.; Turk, J. Structural Characterization of Triacylglycerols as Lithiated Adducts by Electrospray Ionization Mass Spectrometry Using Low-Energy Collisionally Activated Dissociation on a Triple Stage Quadrupole Instrument. J. Am. Soc. Mass Spectrom. 1999, 10, 587-599.
5. Lin, J.-T.; Arcinas, A. Regiospecific Analysis of Diricinoleoylglycerols in Castor (Ricinus communis L.) Oil by Electrospray Ionization-Mass Spectrometry. J. Agric. Food Chem. 2007, 55 2209-2216.

6. Thomas, M. C.; Mitchell, T. W.; Blanksby, S. J. Ozonolysis of Phospholipid Double Bonds During Electrospray Ionization: A New Tool for Structure Determination. J. Am. Chem. Soc. 2006, 128, 58-59.

7. Thomas, M. C.; Mitchell, T. W.; Harman, D. G.; Deeley, J. M.; Murphy, R. C.; Blanksby, S. J. Elucidation of Double Bond Position in Unsaturated Lipids by Ozone Electrospray Ionization Mass Spectrometry. Anal. Chem. 2007, 79, 5013-5022.

8. Thomas, M. C; Mitchell, T. W. Harman, D. G.; Deeley, J. M. Nealon, J. R.; Blanksby, S. J. Ozone-Induced Dissociation: Elucidation of Double Bond Position within Mass-Selected Lipid Ions. Anal. Chem. 2008, 80, 303-311.

9. Hsu, F.-F.; Turk, J. Electrospray Ionization/Tandem Quadrupole Mass Spectrometric Studies on Phosphatidylcholines: The Fragmentation Processes. J. Am. Soc. Mass Spectrom. 2003, 14, 352-363.

10. Hsu, F.-F.; Turk, J. Electrospray Ionization with Low-Energy Collisionally Activated Dissociation Tandem Mass Spectrometry of Glycerophospholipids: Mechanisms of Fragmentation and Structural Characterization. J. Chromatogr. B 2009, 877, 2673-2695.

11. Hsu, F.-F.; Turk, J. Structural Characterization of Unsaturated Glycerophospholipids by Multiple-Stage Linear Ion-Trap Mass Spectrometry with Electrospray Ionization. J. Am. Soc. Mass Spectrom. 2008, 19, 1681-1691.

12. Hsu, F.-F.; Turk, J. Elucidation of the Double Bond Position of LongChain Unsaturated Fatty Acids by Multiple-Stage Linear Ion-Trap Mass Spectrometry with Electrospray Ionization. J. Am. Soc. Mass Spectrom 2008, 19, 1673-1680.

13. Hsu, F.-F.; Turk, J. Studies on Phosphatidylserine by Tandem Quadrupole and Multiple Stage Quadrupole Ion-Trap Mass Spectrometry with Electrospray Ionization: Structural Characterization and the Fragmentation Processes. J. Am. Soc. Mass Spectrom. 2005, 16, 1510-1522.

14. Hsu, F.-F.; Turk, J.; Owens, R. M.; Rhoades, E. R.; Russell, D. G. Structural Characterization of Phosphatidyl-Myo-Inositol Mannosides from Mycobacterium bovis Bacillus Calmette Guerin by Multiple-Stage Quadrupole Ion-Trap Mass Spectrometry with Electrospray Ionization. I. PIMs and Lyso-PIMs. J. Am. Soc. Mass Spectrom. 2007, 18, 466-478.

15. Hsu, F.-F.; Turk, J.; Owens, R. M.; Rhoades, E. R.; Russell, D. G. Structural Characterization of Phosphatidyl-Myo-Inositol Mannosides from Mycobacterium bovis Bacillus Calmette Guerin by Multiple-Stage Quadrupole Ion-Trap Mass Spectrometry with Electrospray Ionization. II. Monoacyl- and Diacyl-PIMs. J. Am. Soc. Mass Spectrom. 2007, 18, $479-492$.

16. Adams, J.; Gross, M. L. Energy Requirement for Remote Charge Site Ion Decomposition and Structural Information from Collisional Activation of Alkali Metal Cationized Fatty Alcohols. J. Am. Chem. Soc. 1986, 108, 6915-6921.

17. McAnoy, A. M.; Wu, C. C.: Murphy, R. C. Direct Qualitative Analysis of Triacylglycerols by Electrospray Mass Spectrometry Using a Linear Ion Trap. J. Am. Soc. Mass Spectrom. 2005, 16, 1498-1509.

18. Momchilova, S.; Tsuji, K.; Itabashi, Y.; Nikolova-Damyanova, B.; Kuksis, A. Resolution of Triacylglycerol Positional Isomers by ReversedPhase High-Performance Liquid Chromatography. J. Sep. Sci. 2004, 27, 1033-1036.

19. Ikeda, K.; Oike, Y.; Shimizu, T.; Taguchi, R. Global Analysis of Triacylglycerols Including Oxidized Molecular Species by Reverse-Phase High Resolution LC/ESI-QTOF MS/MS. J. Chromatogr. B 2009, 877, $2639-$ 2647. 